\section{EMBRYRIDDLE \\ Aeronautical University}

SCHOLARLY COMMONS

\section{International Journal of Aviation,} Aeronautics, and Aerospace

\title{
Effect of Anthropometric Variability on Middle-Market Aircraft Seating
}

Tara C. Sriram

Embry-Riddle Aeronautical University, Worldwide, sriramt@my.erau.edu

Follow this and additional works at: https://commons.erau.edu/ijaaa

Part of the Applied Statistics Commons, Aviation Commons, Ergonomics Commons, and the Industrial and Product Design Commons

\section{Scholarly Commons Citation}

Sriram, T. C. (2018). Effect of Anthropometric Variability on Middle-Market Aircraft Seating. International Journal of Aviation, Aeronautics, and Aerospace, 5(1). https://doi.org/10.15394/ijaaa.2018.1208

This Article is brought to you for free and open access by the Journals at Scholarly Commons. It has been accepted for inclusion in International Journal of Aviation, Aeronautics, and Aerospace by an authorized administrator of Scholarly Commons. For more information, please contact commons@erau.edu. 


\section{Effect of Anthropometric Variability on Middle-Market Aircraft Seating}

\section{Cover Page Footnote}

The author would like to thank Dr. Kent Anderson and Dr. Mark Miller of Embry-Riddle Aeronautical University, Worldwide for their expert guidance and support in the completion of this project. 
A middle-of-market aircraft, or MoMA, is defined as an aircraft capable of flying 180-250 passengers without refueling for 2,300-5,800 miles $(\sim 2,000-5,000$ nautical miles). As the name suggests, middle-of-market aircraft are positioned in between the market segments served by narrow body (single-aisle) and wide body (twin-aisle) aircraft. They are typically used to fly routes that are beyond the range of narrow body aircraft such as the B737 or A320, but not traveled enough to meet the break-even load factors on larger aircraft such as a B777 or A350. It is a challenging market to design for, as it involves offering the range and capacity of a wide body aircraft in the body of a narrow body aircraft.

Nevertheless, nearly $90 \%$ of 507 airlines and air cargo operators responding to a 2016 Penton Aviation Week and Bank of America Merrill Lynch survey confirmed they would be interested in buying a new middle-market jet, and most of them would want it before 2023 (Franzman, 2016). Boeing has also expressed interest in developing a new midsize airplane (NMA) to replace the B757 and B767 and has projected a market entry date of 2025 (Gates, 2016).

Currently, both wide body and narrow body aircraft serve the middlemarket. A range of aircraft models and variants produced by Boeing and Airbus fit the criteria of transporting 180-250 passengers over a range of 2,300-5,800 miles. These include the B787, B767, B757, B737, A330, A321, A320neo, A310, and A300. Middle-market aircraft are typically either the larger variants of narrow body models such as the B737 and A320, or smaller variants of wide body models such as the B787 or A330. The notable exceptions are the B757 and B767.

Aircraft passenger count is determined by seating - the primary commodity an airline sells to its customers. Airlines measure their capacity in terms of available seat kilometers (ASKs), and their performance in terms of cost per ASK (CASK) and revenue per ASK (RASK). The aircraft seat is also the primary touch-point for the passenger experience on all aircraft and plays a significant role in defining an airline's business strategy. This paper presents the findings of a study on the effect of anthropometric variability on economy class seating on middle-market aircraft currently in service, supporting the hypothesis that airlines optimize their aircraft interior configurations based on the anthropometric characteristics of the population they serve.

\section{Literature Review}

Economic seat allocation models have been explored in great detail, but they tend to simplify a critical component of the aviation system - the passenger. For an airline to remain in business, it must be able to retain a loyal customer base. 
Empirical data shows that a $14 \%$ reduction in maintenance costs typically only results in a one percent improvement in an airline's profit margin. On the other hand, increasing passenger revenue by only one percent has the same result (Vink \& Brauer, 2011).

The first and business class cabins receive a great deal of attention from airlines, due to the more significant opportunities for product innovation. However, there is generally less flexibility in service offerings in economy class, even though those seat tickets are considered an airline's 'bread-and-butter.' The more seats an airline can fit on a particular aircraft, the higher a profit it can command the same route. Airline customers typically work directly with Original Equipment Manufacturers (OEMs) to develop an Aircraft Interior Customisation Document or Layout of Passenger Accommodations (LOPA). The Federal Aviation Administration (FAA) defines a LOPA as an engineering diagram that documents the layout of the aircraft's cabin interior, including seats, exits, lavatories, and galleys, among other commodities. Depending on whether an airline selects a single-class, two-class, or three-class seating configuration, airlines can exercise a great deal of control over the number of seats it sells per route. A critical parameter in LOPA and seat configurations is seat pitch, which refers to the distance between the same two points between two successive rows of seats.

Vink and Brauer (2011) conducted a thorough empirical survey of 10,032 passengers in order to precisely determine the extent to which in-flight variables affected passenger comfort. They determined that legroom, hygiene, and crew service were the three primary variables affecting comfort ratings. Legroom was considered comfortable when the passenger was able to stretch their legs out under the seat in front of them, and quickly adjust their seating position.

\section{Legroom vs. Seat Pitch}

Vink and Brauer (2011) make a critical distinction between seat pitch and legroom. The general perception is that a larger seat pitch equates to more legroom, and therefore a more comfortable seat. This is an inaccurate assumption: seat pitch refers to the distance between the same two points on two successive rows of seats and is not representative of the available legroom. Legroom is determined by the design of the seat product itself, and primarily affected by the contour and thickness of the seat back cushion. For example, a 33-inch seat pitch with a three-inch thick backrest cushion would create less legroom than a 31-inch seat pitch with a oneinch thick backrest. 


\section{Neighbors}

Vink and Brauer (2011) also identified the presence of a neighbor as a factor affecting passenger comfort. While this variable was only mentioned by less than $8 \%$ of the passengers surveyed, not having a neighbor or having only one neighbor had a significant impact on comfort ratings. This suggests that the configuration of aircraft seat rows within the interior cabin has an effect on perceived comfort.

Based on the studies conducted by Vink and Brauer (2011), Kremser, Guenzkofer, Sedlmeier, Sabbah, and Bengler (2012) conducted an empirical study to evaluate the impact of legroom and seat-pitch on passenger well-being. They found that increasing seat pitch contributed to the sense of comfort as participants found it easier to adopt a comfortable posture and adjust their seating position. However, the study also found that there is a maximum level of overall well-being, dependent on the buttock-to-knee length and seat pitch.

Aircraft seats are incredibly challenging products to design. There is simply no other type of seating that must accommodate such a wide variety of body types in such a confined space for such extended periods of time (Vink \& Brauer, 2011). The human body varies significantly across populations, ethnicities, races, genders, and ages, and the sheer diversity of anthropometric characteristics makes it challenging to accommodate the needs of all members of the population.

The FAA Human Factors guidelines only require aircraft interiors to accommodate the needs of $5^{\text {th }}$ percentile females to $95^{\text {th }}$ percentile males (Ahlstrom \& Longo, 2003). However, there is tremendous variability even within those limits: the $5^{\text {th }}$ percentile stature is $1440 \mathrm{~mm}$ (4 ft. 9 in.) among South-East Asian women, and $1580 \mathrm{~mm}$ (5 ft. 2 in.) among Northern European women (Jurgens, Aune, \& Pieper, 1990). The needs of outlying populations, such as children, elderly people, and physically disabled people are typically given lower priority when designing seat products.

\section{Methodology}

This study examined 1) whether there was a statistically significant difference in the mean seat pitch of US and Asian airlines on middle-of-market aircraft (MoMA) produced by Boeing and Airbus, and 2) whether there was a statistically significant difference in the distribution of seat configurations selected by US and Asian airlines on middle-of-market aircraft (MoMA) produced by Boeing and Airbus. Seat pitch and seat configuration are selected as the primary 
variables of the study because they determine the total seat count for a particular seat class on an aircraft.

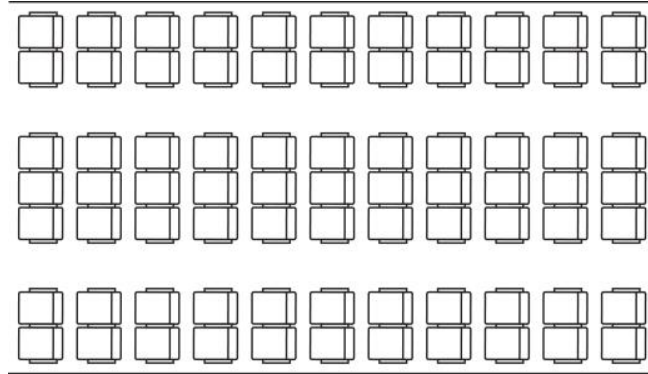

Seat pitch: 33 inches (11 rows)

Seat configuration: 2-3-2 (7-abreast)

Total seats: $11 \times 7=\underline{77 \text { seats }}$
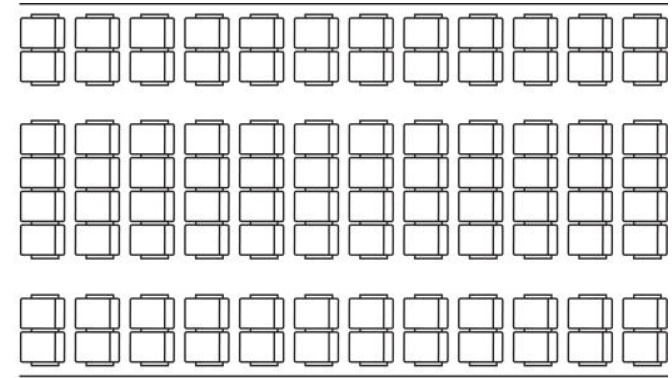

Seat pitch: 31 inches (12 rows)

Seat configuration: $2-4-2$ (8-abreast)

Total seats: $12 \times 8=\underline{96 \text { seats }}$

Figure 1. Seat pitch and seat configuration have a combined impact on total seat count. For a particular fuselage width and section of fuselage length, a 2-3-2 seat configuration pitched at 33 inches can accommodate 77 seats. On the other hand, for the same fuselage section, a 2-4-2 seat configuration pitched at 31 inches can accommodate 96 seats. The tighter seat pitch adds an extra row of seats, while the denser seat configuration adds an extra seat per row, leading to a combined 19 additional seats. Each additional seat has a significant impact on the revenue generated by a flight.

As discussed previously, a MoMA is defined as an aircraft capable of flying 180-250 passengers without refueling for 2,300-5,800 miles ( 2,000-5,000 nautical miles). These parameters are based on Boeing's and the broader aviation industry's definition of middle-market aircraft. The sample data consisted of 130 unique aircraft LOPAs from two equally sized groups of US and Asian airlines. The study focused on the A321, A330-200, B737-800, B737-900, B757, B767, and B787-8. These are aircraft currently in service that met the seat capacity parameters of this study.

Seat pitch, seat configurations, aircraft type, and airline data was gathered from SeatGuru.com's seat comparison database. US airlines included Alaska, Allegiant, American, Delta, Frontier, jetBlue, Southwest, Spirit, Sun Country, and United Airlines. Asian airlines included Air China, Air India, All Nippon Airways (ANA), Asiana, China Airlines, China Eastern Airlines, China Southern Airlines, Dragonair, EVA Air, Garuda Indonesia, Hainan Airlines, Japan Airlines, Jet Airways, Korean Air, Lion Airlines, Malaysia Airlines, Nok Air, SpiceJet, SriLankan Airlines, Vietnam Airlines, and Xiamen Airlines. 


\section{Variables of the Study}

Seat Pitch. Seat pitch refers to the distance between the same two points on two successive rows of seats. In other words, it determines the number of rows of seats an airline can fit into an aircraft of a given size. For economy class, seat pitches typically range between 29 and 32 inches (Kremser et al., 2012). Premium economy class seats tend to offer more substantial seat pitches ranging from 33 to 35 inches. A tighter seat pitch allows an airline to accommodate more seats in the cabin and therefore generate more revenue - however, it reduces the available legroom and can compromise passenger comfort.

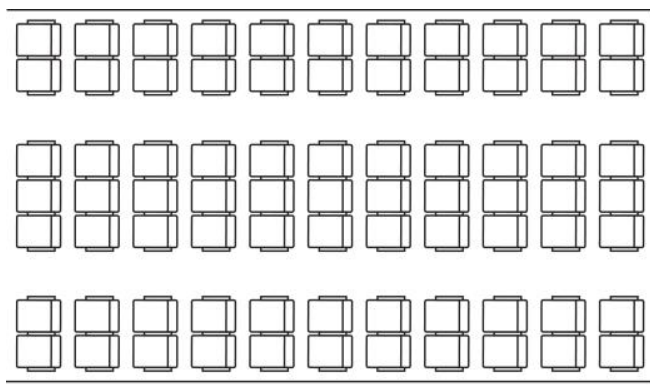

Seat pitch: 33 inches (11 rows)

Seat configuration: 2-3-2 (7-abreast)

Total seats: $11 \times 7=\underline{77 \text { seats }}$
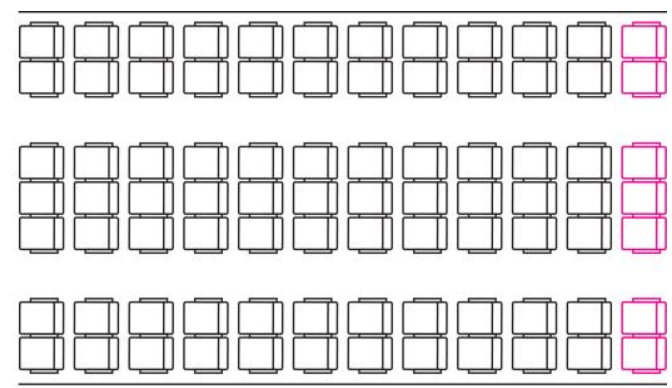

Seat pitch: 31 inches (12 rows)

Seat configuration: 2-3-2 (7-abreast)

Total seats: $12 \times 7=\underline{84}$ seats

Figure 2. Tighter seat pitches allow airlines to accommodate additional rows of seats. For a particular fuselage width and section of fuselage length, a 2-3-2 seat configuration pitched at 33 inches can accommodate 77 seats. On the other hand, the same configuration pitched at 31 inches can accommodate an additional twelfth row, for a total of 84 seats.

For Boeing and Airbus, and most other aircraft OEMs, seat pitch is customizable in discrete one-inch increments that are determined by modular floormounted seat tracks. As a result, the data did not follow a normal distribution. Thus non-parametric analysis was used to compare results.

Table 1

US and Asia seat pitch $\left(P_{u}, P_{a}\right)$ summary statistics

\begin{tabular}{|c|c|c|c|c|c|}
\hline & $\underline{\mathrm{n}}$ & Mean $(\mu)$ & Std. dev. $(\sigma)$ & Std. Error & Median \\
\hline$P_{u}$ & $\overline{65}$ & $33.35\left(\mu_{\mathrm{u}}\right)$ & $2.43\left(\sigma_{\mathrm{u}}\right)$ & 0.30 & 34 \\
\hline$P_{a}$ & 65 & $31.95\left(\mu_{\mathrm{a}}\right)$ & $1.41\left(\sigma_{\mathrm{a}}\right)$ & 0.17 & 31.5 \\
\hline
\end{tabular}


Seat Configuration. Seat configuration refers to the number of seats per row for a given aircraft. The width of an aircraft fuselage is primarily driven by the desired seat configuration (Vink \& Brauer, 2011). For example, a B737 narrow body is designed to accommodate a 3-3 seat configuration with a single aisle, while the A330 wide body is designed to accommodate a 2-4-2 seat configuration with two aisles. A chi-square test for independence was used to determine whether there was preferred seat configuration for each of the two groups, US and Asian airlines.

Seat Configuration vs. Seat Width. Seat configuration, in addition to the aircraft fuselage width and the aisle width, has a significant influence on seat width. For example, the A330, which has a 19-foot fuselage diameter, can accommodate either a 2-4-2, eight abreast seat configuration with 18" seats, or a high density, 33-3, nine abreast seat configuration with 16.7" seats (RGN, 2017). The FAA and ICAO regulate aisle widths in order to ensure speedy passenger egress in an emergency. For scheduled commercial aircraft with 20 or more passengers, the aisle width must be maintained at a minimum 20 inches at the height of 25 inches above the interior cabin floor (14 C.F.R. $\$ 25.815,2017)$.

Similar to the distinction between seat pitch and legroom, seat configuration can be viewed as a measure of capacity, while seat width is the measure of comfort. However, the literature review found that the presence of a neighbor also has an influence on comfort, suggesting that less dense seat configurations are more comfortable.

\section{Results}

\section{Seat Pitch}

A Mann Whitney $U$ test was used to determine whether the difference in means between the two sample groups was statistically significant. The null and alternate hypotheses of the test were as follows:

- $\mathrm{H}_{0}$ : there is no difference between the mean seat pitch of US and Asian airlines

- $\mathrm{H}_{\alpha}$ : there is a difference between the mean seat pitch of US and Asian airlines

A confidence level of $\alpha=0.05$ was used. 

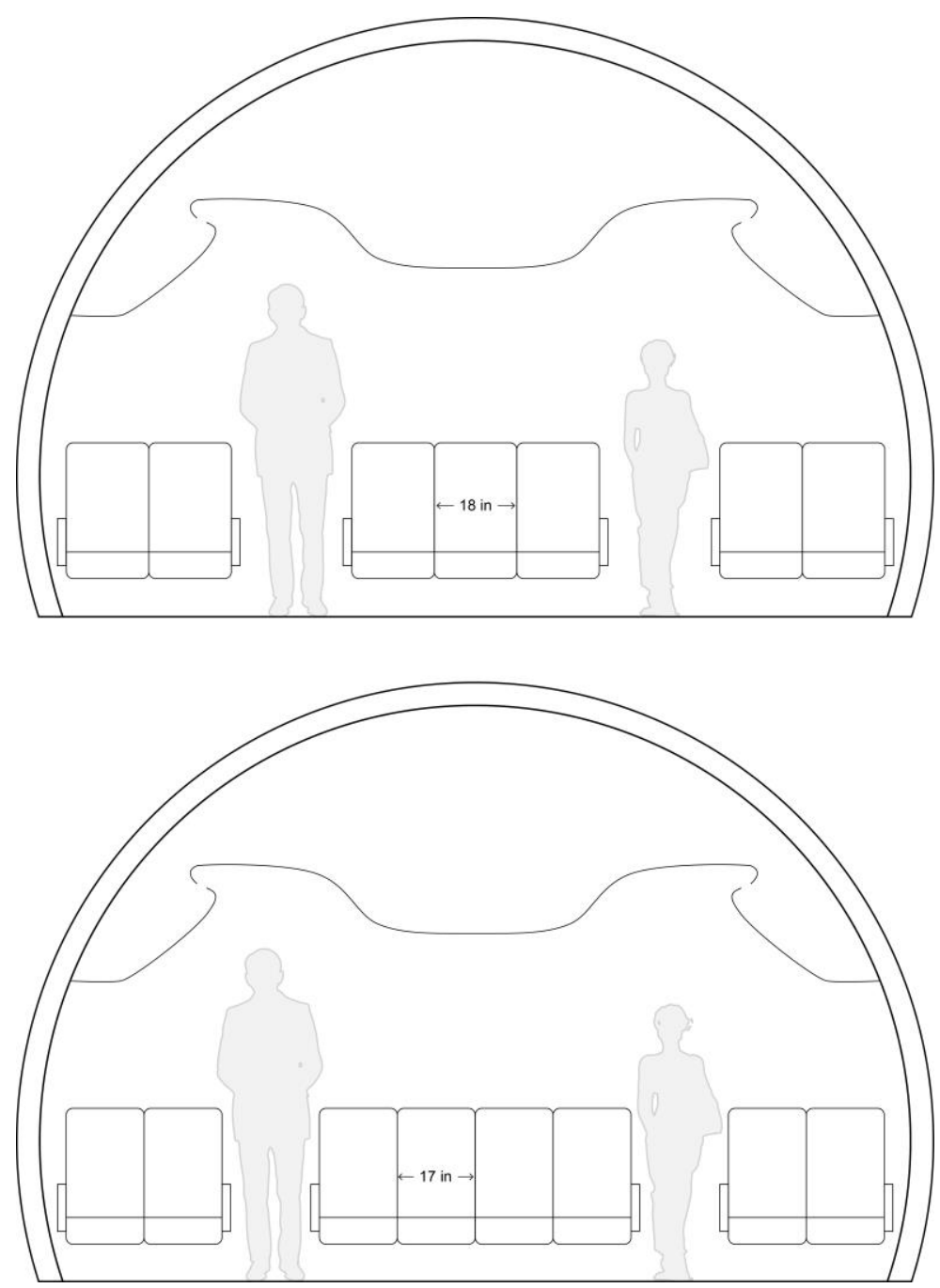

Figure 3. Influence of seat configuration on seat width 
The Mann-Whitney $U$ test was used to obtain a comparative result. The MannWhitney test indicated that the seat pitch was greater for US airlines $(M d n=34)$ than for Asian airlines $(\mathrm{Mdn}=31.5), U=4977.5, p=0.0007$.

\section{Seat Configuration}

A chi-square test for independence was used to determine whether there was preferred seat configuration for each of the two groups, US and Asian airlines. It was expected that geographic region (US airlines v/s Asian airlines) would not have an influence on the frequency of narrow body seat configurations (3-3) versus wide body seat configurations (2-3-2, 2-4-2, and 3-3-3). A 95\% confidence interval was selected to test the null hypothesis. The chi-square goodness-of-fit test's null and alternate hypotheses are given as follows:

- $\mathrm{H}_{0}$ : Geographic region and seat configuration are independent, or

- $\mathrm{H}_{\alpha}$ : Geographic region and seat configuration are dependent

The results were significant, $\chi^{2}(3, N=130)=7.907, p=0.048$. As such, the null hypothesis of variable independence was rejected.

\section{Discussion}

The quantitative study demonstrated a statistically significant difference in the mean seat pitch between the sampled middle-market LOPAs of US and Asian airlines, and that seat configuration and geographic region were dependent variables. As identified by the literature review, the human body varies greatly across countries, ethnicities, races, genders, and ages, and the sheer diversity of anthropometric characteristics makes it extremely challenging to accommodate the needs of all members of the population. The FAA's Human Factors Design Standard mandates that aircraft systems and equipment shall be, at a minimum, designed for personnel from the $5^{\text {th }}$ through the $95^{\text {th }}$ percentile levels of the human physical characteristics that represent the user population (Ahlstrom \& Longo, 2003 , p. 2-7). 'User population' is open to a wide range of interpretations, and the $5^{\text {th }}$ and $95^{\text {th }}$ percentile limits vary drastically between subsets of the human population.

Tables 2 and 3 summarize the differences between the $5^{\text {th }}$ and $95^{\text {th }}$ percentiles of critical seating-related measures of North American and South Chinese male and female populations. Popliteal height is the distance from the underside of the foot to the underside of the knee. Buttock-to-knee length is the distance measured horizontally from the rearmost part of the buttocks to the front of the knee. As these two measures increase, more space is needed for the person to be able to stretch their legs out in front of them while seated. In other words, the larger these two measures, the greater the legroom needed to make the person feel comfortable.

Bideltoid breadth is the maxmium horizontal distance across the shoulders, measured to the protrusions of the deltoid muscles. Seated hip breadth is measured between 
the crests of the hipbones. As these two measures increases, so will the width of the seat back and seat pan needed for the person to feel comfortable.

The general consensus in human factors and product design is that by designing for the highest level of the population, the needs of the other members will be met (HFES, 2004). In this case, the highest popliteal height, buttock-to-knee length and bideltoid measures are from the $95^{\text {th }}$ percentile male populations. The largest seated hip breadth measure is from the $95^{\text {th }}$ percentile female population. However, there is tremendous variation between the $95^{\text {th }}$ percentile levels of the North American population and South Chinese population.

Table 2

Differences in $5^{\text {th }}$ and $95^{\text {th }}$ percentile levels for males between geographic regions. Compiled from Jurgens, Aune, \& Pieper, 1990.

\begin{tabular}{|c|c|c|c|c|}
\hline Physical Measure & $95^{\text {th }} \%(\mathrm{~N} \mathrm{Am})$ & $95^{\text {th } \%(\mathrm{~S} \mathrm{Ch})}$ & $5^{\text {th } \%(\mathrm{~N} \mathrm{Am})}$ & $5^{\text {th } \%(\mathrm{~S} \mathrm{Ch})}$ \\
\hline Popliteal height & $\begin{array}{l}500 \mathrm{~mm} \\
(19.685 \mathrm{in})\end{array}$ & $\begin{array}{l}445 \mathrm{~mm} \\
(17.520 \mathrm{in})\end{array}$ & $\begin{array}{l}405 \mathrm{~mm} \\
(15.945 \mathrm{in})\end{array}$ & $\begin{array}{l}380 \mathrm{~mm} \\
(14.961 \mathrm{in})\end{array}$ \\
\hline Buttock-to-knee length & $\begin{array}{l}660 \mathrm{~mm} \\
(25.984 \mathrm{in})\end{array}$ & $\begin{array}{l}580 \mathrm{~mm} \\
(22.834 \mathrm{in})\end{array}$ & $\begin{array}{l}550 \mathrm{~mm} \\
(21.654 \mathrm{in})\end{array}$ & $\begin{array}{l}490 \mathrm{~mm} \\
(19.291 \mathrm{in})\end{array}$ \\
\hline Bideltoid breadth & $\begin{array}{l}500 \mathrm{~mm} \\
(19.685 \mathrm{in})\end{array}$ & $\begin{array}{l}430 \mathrm{~mm} \\
(16.929 \mathrm{in})\end{array}$ & $\begin{array}{l}420 \mathrm{~mm} \\
(16.535 \mathrm{in})\end{array}$ & $\begin{array}{l}380 \mathrm{~mm} \\
(14.961 \mathrm{in})\end{array}$ \\
\hline Seated hip breadth & $\begin{array}{l}400 \mathrm{~mm} \\
(15.748 \mathrm{in})\end{array}$ & $\begin{array}{l}340 \mathrm{~mm} \\
(13.386 \mathrm{in})\end{array}$ & $\begin{array}{l}310 \mathrm{~mm} \\
(12.205 \mathrm{in})\end{array}$ & $\begin{array}{l}290 \mathrm{~mm} \\
(11.417 \mathrm{in})\end{array}$ \\
\hline
\end{tabular}

Note: $\mathrm{N}$ Am $=$ North America; $\mathrm{S} \mathrm{Ch}=$ South China 
Table 3

Differences in $5^{\text {th }}$ and $95^{\text {th }}$ percentile levels for females between geographic regions. Compiled from Jurgens, Aune, \& Pieper, 1990.

\begin{tabular}{|c|c|c|c|c|}
\hline Physical Measure & $95^{\text {th }} \%(\mathrm{~N} \mathrm{Am})$ & $95^{\text {th }} \%(\mathrm{~S} \mathrm{Ch})$ & $5^{\text {th }} \%(\mathrm{~N} \mathrm{Am})$ & $5^{\text {th }} \%(\mathrm{~S} \mathrm{Ch})$ \\
\hline Popliteal height & $\begin{array}{l}450 \mathrm{~mm} \\
(17.717 \mathrm{in})\end{array}$ & $\begin{array}{l}405 \mathrm{~mm} \\
(15.945 \mathrm{in})\end{array}$ & $\begin{array}{l}360 \mathrm{~mm} \\
(14.173 \mathrm{in})\end{array}$ & $\begin{array}{l}365 \mathrm{~mm} \\
(14.370 \mathrm{in})\end{array}$ \\
\hline Buttock-to-knee length & $\begin{array}{l}520 \mathrm{~mm} \\
(20.475 \mathrm{in})\end{array}$ & $\begin{array}{l}530 \mathrm{~mm} \\
(20.866 \mathrm{in})\end{array}$ & $\begin{array}{l}520 \mathrm{~mm} \\
(20.475 \mathrm{in})\end{array}$ & $\begin{array}{l}470 \mathrm{~mm} \\
(18.504 \mathrm{in})\end{array}$ \\
\hline Bideltoid breadth & $\begin{array}{l}430 \mathrm{~mm} \\
\text { (16.929 in) }\end{array}$ & $\begin{array}{l}410 \mathrm{~mm} \\
(16.142 \mathrm{in})\end{array}$ & $\begin{array}{l}370 \mathrm{~mm} \\
(14.567 \mathrm{in})\end{array}$ & $\begin{array}{l}340 \mathrm{~mm} \\
(13.386 \mathrm{in})\end{array}$ \\
\hline Seated hip breadth & $\begin{array}{l}430 \mathrm{~mm} \\
(16.929 \mathrm{in})\end{array}$ & $\begin{array}{l}400 \mathrm{~mm} \\
(15.748 \mathrm{in})\end{array}$ & $\begin{array}{l}310 \mathrm{~mm} \\
(12.205 \mathrm{in})\end{array}$ & $\begin{array}{l}330 \mathrm{~mm} \\
(12.992 \mathrm{in})\end{array}$ \\
\hline
\end{tabular}

From Table 2, the $95^{\text {th }}$ percentile popliteal height of North American males is 55 $\mathrm{mm}$ (2.165 in) greater than the $95^{\text {th }}$ percentile popliteal height length of South Chinese males. The $95^{\text {th }}$ percentile buttock-to-knee length of North American males is $80 \mathrm{~mm}$ ( 3.150 in) greater than the $95^{\text {th }}$ percentile buttock-to-knee length of South Chinese males. The $95^{\text {th }}$ percentile bideltoid breadth of North American males is $70 \mathrm{~mm}$ (2.756 in) greater than the $95^{\text {th }}$ percentile bideltoid breadth of South Chinese males. From Table 3, the $95^{\text {th }}$ percentile seated hip breadth of North American females is $30 \mathrm{~mm}$ (1.811 in) greater than the $95^{\text {th }}$ percentile seated hip breadth length of South Chinese females.

At first glance, these differences are in mere inches. However, in the aviation industry, mere inches have a profound impact on the number of seats an airline can accommodate on the aircraft - and therefore a profound impact on the revenue generated by a flight. The following sections qualitatively discuss the impact of the above anthropometric differences on 1) seat pitch and legroom; and 2) seat configuration and seat width. 


\section{Seat Pitch and Legroom}

The difference in seat pitch could potentially be attributed to the fact that Asian populations, on average, tend to have shorter statures than their American counterparts. In particular, the $95^{\text {th }}$ percentile buttock-to-knee length of North American males is $660 \mathrm{~mm}$ (25.984 in), while the $95^{\text {th }}$ percentile buttock-to-knee length of South Chinese males is 570 $\mathrm{mm}$ (22.441 in). This difference could have a profound impact on the seat pitch considered comfortable by the $95^{\text {th }}$ percentile levels of the different populations.

The literature review identified legroom as one of the most critical factors contributing to passenger comfort while seated in economy class on an aircraft. Legroom is not always determined by the seat pitch, but rather by some factors specific to the seat design, such as the thickness of the seat cushion and contouring of the seat back. However, the same seat pitched differently would create different amounts of legroom. Kremser et al. (2012) identified that passengers experienced a maximum level of comfort at particular seat pitches based on their buttock-to-knee length. Therefore, the clearance between a passenger's knee and the seat back in front of them could be interpreted as another measure of legroom.

The same seat pitched differently would generate the same amount of knee clearance for the different $95^{\text {th }}$ percentile male buttock-to-knee levels of North American and South Chinese populations. The $95^{\text {th }}$ percentile buttock-to-knee length of North American males is $660 \mathrm{~mm}$ (25.984), while the $95^{\text {th }}$ percentile buttock-to-knee length of South Chinese males is $580 \mathrm{~mm}$ (22.834 in). This amounts to a difference of $80 \mathrm{~mm}$ (3.15 in). Therefore, the same seat pitched at 30 inches for $95^{\text {th }}$ percentile male South East Asian travelers and 33 inches for $95^{\text {th }}$ percentile male North American travelers could be considered equally comfortable.

This difference in seat pitch could have a significant impact on the revenue generated by a flight. For example, China Southern Airlines operates an Airbus 330-300 non-stop from Beijing Capital International Airport to Guangzhou Baiyun International Airport with 197 economy class seats pitched at 33 inches, configured eight and seven abreast. Assuming an average round trip economy fare of US \$600, the flight can generate US $\$ 118,200$ from its economy cabin. The same cabin pitched at 30 inches can accommodate an additional 16 seats, generate US $\$ 127,800$, and increase its revenue by over $8 \%$.

Furthermore, if the majority of the traveling population on that flight was local, there is evidence to suggest the 30 -inch pitch would be considered equally comfortable as the 33-inch pitch. This example simplifies many other considerations such as route demand and load factors, but it illustrates the impact of seat pitch on revenue. 
$95^{\text {th }}$ percentile male buttock-to-knee length (North America)

$95^{\text {th }}$ percentile male buttock-to-knee length (South China)

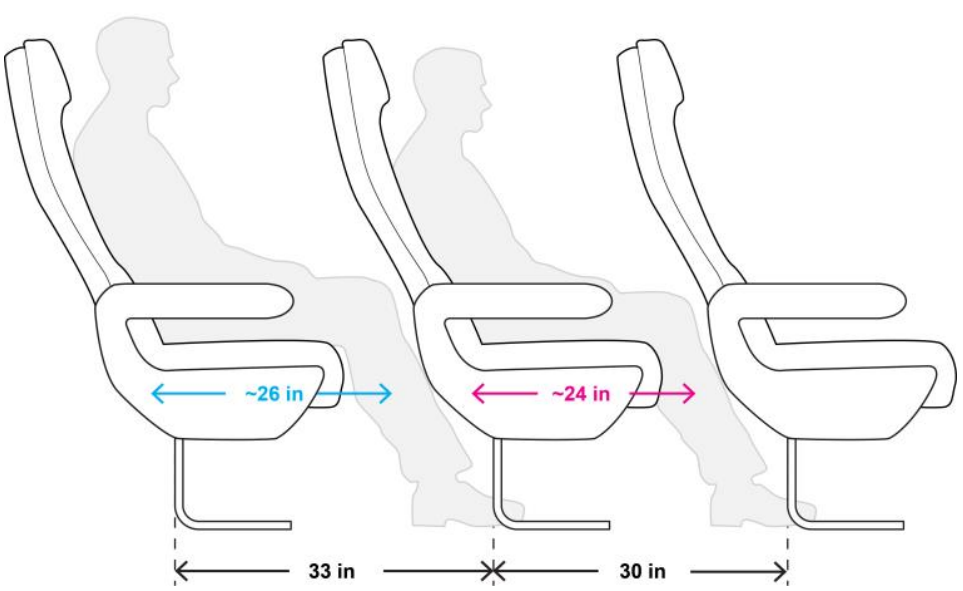

Figure 4. The same seat pitched differently creates the same amount of knee clearance for different $95^{\text {th }}$ percentile levels for North American and South Chinese populations.

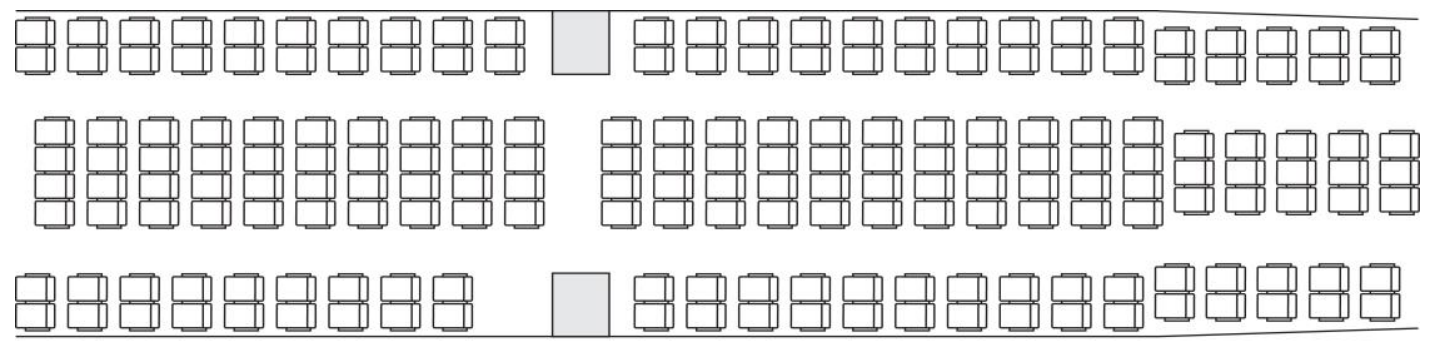

Seat pitch: 33 inches (26 rows)

Seat configuration: 2-4-2 (8-abreast) and 2-3-2 (7 abreast)

Total seats: $(9 \times 8)+(1 \times 6)+(1 \times 4)+(10 \times 8)+(5 \times 7)=\underline{197 \text { seats }}$

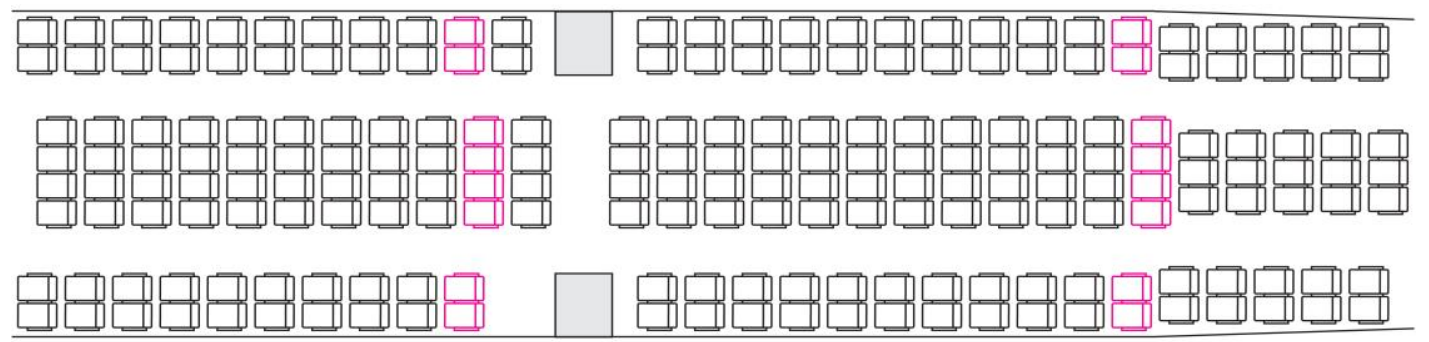

Seat pitch: 31 inches (28 rows)

Seat configuration: 2-4-2 (8-abreast) and 2-3-2 (7 abreast)

Total seats: $(10 \times 8)+(1 \times 6)+(1 \times 4)+(11 \times 8)+(5 \times 7)=\underline{\mathbf{2 1 3} \text { seats }}$

Figure 5. Different anthropometrically optimized LOPAs and subsequent changes in seat count based on the different seat pitches. Adapted from seatguru.com (2017). 


\section{Seat Configuration and Seat Width}

The study found that among the 130 middle-market LOPAs sampled; there was a significant dependence between seat configuration (3-3, 2-3-2, 2-4-2, and 3-3-3) and geographic region (US and Asian airlines). The preference for narrow body aircraft can be attributed to the fact that $57 \%$ of the 23,500 aircraft in service as of 2016 are Boeing and Airbus narrow bodies - a total of 13,500 aircraft (ALAFCO, 2016). In the wide body category, the Asian airlines' apparent preference for denser seating configurations, and therefore larger aircraft implies there is a need to reduce the frequency of flights and move larger groups of people more efficiently.

The literature review identified that the presence of a neighbor had an influence on passenger comfort. The study by Vink and Brauer (2011) identified that having two neighbors was considered less comfortable than having one neighbor. This implies that specific seating configurations are more comfortable than others, as demonstrated in Figure 6. For middle-market aircraft, in particular, the 2-3-2 seat, seven abreast configuration can be considered the most comfortable, while the 3-3-3, nine abreast configurations is the least comfortable. This is because the 2-3-2 configuration only has one seat with two neighbors, while the 3-3-3 configuration has three seats with two neighbors. Both the 3-3, six abreast configuration and 2-4-2, eight abreast configuration have two seats with two neighbors.
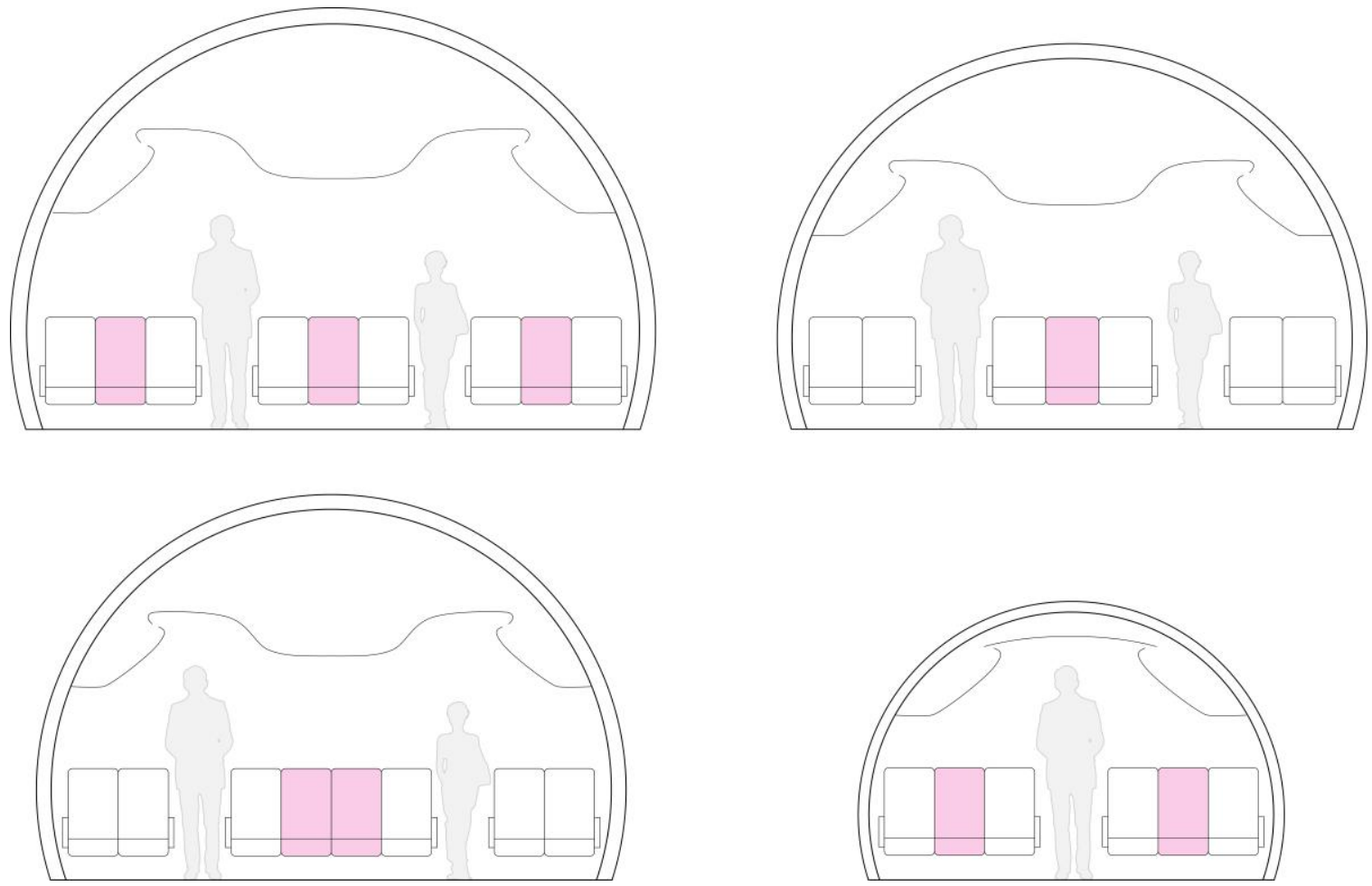

Figure 6. Certain configurations have more uncomfortable seats than others. 
As previously illustrated in Figure 3, seat configuration, seat width, aisle width, and fuselage diameter are all interdependent variables. As the $95^{\text {th }}$ percentile bildeltoid widths and sitting hip breadths vary between populations so does the width of seat considered comfortable. To accommodate a wider North American male, the seat may need to be 20 inches wide. On the other hand, 17 inches could be sufficient for narrower South Chinese male.

Today, the only aircraft fuselage diameter capable of accommodating both 2-3-2 and 2-4-2 seating configurations is the 16.5-foot Boeing 767. Larger aircraft such as the B787 and A330 are simply too large to justify the economics of 2-3-2, seven abreast configurations. Smaller narrow bodies cannot fit the additional seventh seat. While the B767 is 'just right,' it has not been produced as a passenger aircraft since the mid-2000s (Boeing, 2017a). The majority of the B767s in service would be replaced by 2030 .

\section{Further Research}

This paper presented the findings of a study on the effect of anthropometric variability on economy class seating on middle-market aircraft currently in service. The sample was thus limited to 130 unique aircraft LOPAs from two equally sized groups of US and Asian airlines, and only included configurations of the A321, A330-200, B737800, B737-900, B757, B767, and B787-8. The methodology utilized in this study could be further applied to other segments of the aviation market, such short-haul domestic travel or long-haul international travel. It could also be applied to study differences between other geographic regions - for example, Middle Eastern and European carriers.

\section{Limitations of the Analysis}

Due to the limitations in availability of LOPA data, the two groups of the study were bucketed as US airlines and Asian airlines. The countries represented in the Asian airline's group were China, India, Japan, South Korea, Taiwan, Indonesia, Thailand, Malaysia, Sri Lanka, and Vietnam. The populations of these countries comprise of several unique races and ethnicities, yet for the study were treated as a single anthropometric group. They also fall into different geographic regions of Asia, i.e., South, Southeast, East, and Central Asia. This could be a potentially confounding variable of the study. The increased availability of LOPA data could allow future research to explore the differences within Asian countries, for example, whether there is a difference in seating configurations among Chinese and Indian airlines.

\section{Conclusion}

The findings of the study support the hypothesis that airlines optimize their aircraft interior configurations based on the anthropometric characteristics of the population they serve. There is evidence to suggest that these anthropometrically optimized LOPAs would not significantly alter the perceived comfort of the aircraft seat for the local population. The economic benefits of anthropometrically optimized LOPAs are obvious, but they raise many ethical challenges for airlines. While an Asian, domestic carrier may be able to use 
a more compact seat configuration to accommodate smaller Asian bodies, it comes at the risk of greatly inconveniencing the larger European and American traveler, as well as other outliers in the population.

This study highlights the variations in economy class seating between airlines and suggests that the guidance of designing to accommodate only the needs of $95^{\text {th }}$ to $5^{\text {th }}$ percentile levels is open to a wide range of interpretations. More rigorous, human-centered comfort standards need to be developed for aviation seating to avoid excluding the needs of outliers and extreme populations. 


\section{References}

Aeronautics and Space, 14 C.F.R. §25.813 (2017).

Aeronautics and Space, 14 C.F.R. $\$ 25.815$ (2017).

Ahlstrom, V., \& Longo, K. (2003). Human factors design standard (HF-STD-001). Atlantic City International Airport, NJ: Federal Aviation Administration William J. Hughes Technical Center.

Airbus. (2016). Mapping demand: Global market forecast 2016-2035. Retrieved from http://www.airbus.com/company/market/global-market-forecast-20162035/?eID=maglisting_push\&tx_maglisting_pi1\%5BdocID\%5D=109228

Anselmo, J., \& Flottau, J. (2016). Airlines to Boeing: 'Get moving' on middle of the market aircraft. Aviationweek.com. Retrieved 1 April 2017, from http://aviationweek.com/commercial-aviation/airlines-boeing-get-moving-middlemarket-aircraft

ALAFCO Aviation Lease and Finance Co. K.S.C.P. (ALAFCO). (2016). Aircraft market chartbook. Retrieved from http://www.alafcokw.com/upload/Media_Library_March_2016___Aircraft_Market_Report_Ma rch_2016_921.pdf

Boeing. (2016). Boeing: About our market. Retrieved September 20, 2016, from http://www.boeing.com/commercial/market/

Boeing. (2017). Historical snapshot: 767 commercial transport/KC-46. Boeing.com. Retrieved from http://www.boeing.com/history/products/767.page

Clark, P. (2007). Buying the big jets: Fleet planning for airlines. Burlington, VT; Aldershot, England; Ashgate Pub. doi:10.4324/9781315570655

Dunk, N. M., \& Callaghan, J. P. (2005). Gender-based differences in postural responses to seated exposures. Clinical Biomechanics, 20(10), 1101-1110. doi: 10.1016/j.clinbiomech.2005.07.004

Franzman, M. (2016, July 10). Penton aviation week network/BofA Merrill Lynch global research study: 89\% of airlines interested in buying middle-of-market aircraft. Retrieved from Uncategorized, http://www.penton.com/penton-aviation-weeknetworkbofa-merrill-lynch-global-research-study-89-of-airlines-interested-inbuying-middle-of-market-aircraft/

Human Factors and Ergonomics Society (HFES). (2004). Guidelines for using anthropometric data in product design. Santa Monica, CA: Human Factors \& Ergonomics Society. 
Johnsson, J. (2015). Boeing in talks on 757 successor as Airbus lands buyer. Bloomberg.com. Retrieved from https://www.bloomberg.com/news/articles/2015-01-13/boeing-in-talks-on-757successor-as-airbus-contender-lands-buyer

Jurgens, H., Aune, I., \& Pieper, U. (1990). International data of anthropometry (1st ed.). Geneva: International Labour Office, Germany.

Kremser, F., Guenzkofer, F., Sedlmeier, C., Sabbah, O., \& Bengler, K. (2012). Aircraft seating comfort: The influence of seat pitch on passengers' well-being. Work (Reading, Mass.), 41 Suppl 1, 4936.

Leon, S. M., Szmerekovsky, J. G., \& Tolliver, D. D. (2013). A portfolio approach to allocating airline seats. Transportation Journal, 52(4), 441-462. doi: 10.5325/transportationj.52.4.0441

Li. Z.F., Zhang, A., \& Zhang, Y. (2008). Airline seat allocation competition. International Transactions in Operational Research, 15(4), 439-459. doi: 10.1111/j.1475-3995.2008.00642.x

Noack, T. (2017). Production list index. Planespotters.net. Retrieved from https://www.planespotters.net/production-list/index

Pheasant, S., \& Haslegrave, C. (2006). Bodyspace (1st ed.). Boca Raton, FL.: Taylor \& Francis.

Runway Girl Network (RGN). (2017, February 13). Lufthansa does not support Airbus campaign for 18-inch seat width standard. Retrieved from https://runwaygirlnetwork.com/2013/11/10/update-lufthansa-does-not-supportairbus-campaign-to-make-18-inches-the-standard-for-seat-width/

Seatguru.com. (2017). Airline Seat Comparison Charts. Retrieved from https://www.seatguru.com/charts/generalcharts.php

Vink, P., \& Brauer, K. (2011;2016;). Aircraft interior comfort and design (1st ed.). Boca Raton, FL: CRC Press. 